\title{
Degradation and mineralization of dyes with advanced oxidation processes (AOPs): A brief review
}

\author{
Wanqian Guo ${ }^{1, a^{*}, \text { Zizeng Yang }}{ }^{2, b}$, Xian-Jiao Zhou ${ }^{3, c}$ and Quli Wu ${ }^{4, d}$ \\ ${ }^{1}$ Harbin Institute of Technology, State Key Laboratory of Urban Water Resource and Environment, \\ 73 Huanghe Road, Harbin, Heilongjiang, 150090, P. R. China \\ ${ }^{2}$ Harbin Institute of Technology, State Key Laboratory of Urban Water Resource and Environment, \\ 73 Huanghe Road, Harbin, Heilongjiang, 150090, P. R. China \\ ${ }^{3}$ Harbin Institute of Technology, State Key Laboratory of Urban Water Resource and Environment, \\ 73 Huanghe Road, Harbin, Heilongjiang, 150090, P. R. China \\ a guowanqian@126.com, byzizeng@163.com, c491731180@qq.com, d944714032@qq.com
}

Keywords: dyes degradation; ozonation; Fenton; wet air oxidation

Abstract. The discharge of wastewater which contains dyes, represents serious environmental problem and receives public health concern. It has become a big challenge to degrade and mineralize these dyes. Advanced oxidation processes (AOPs), based on the production of hydroxide radicals are effective methods to treat the dye wastewater compared with other methods. This paper reviews the current available AOPs that are effective to degrade and mineralize dyes.

\section{Introduction}

With the strong demand for textile products, the generation of wastewater that contains dyes has increased proportionally, making it become one of the main sources of severe pollution problems worldwide [1]. In particular, more and more dyes have been used and then discharged into the environment. Dye-containing wastewater has aroused increasing attention because most of the dyes molecules have complicated structures and they are photostable. Thus, they are resistant toward conventional biological decomposition. Moreover, other chemical and physical treatments are not quite proper because of the secondary pollution [2]. So there is a urgent need for the development of some efficient and feasible methods for dyes removal from wastewater.

Advanced oxidation processes (AOPs) are considered to be promising methods for hazardous toxic organic pollutants treatment in aqueous solutions[3]. AOPs have provided innovative potential to oxidize the majority of organic compounds present in the wastewater. They have been proved to be extremely useful for the substances resistant to conventional technologies[4]. This paper has reviewed the studies of the most widely used methods of dye degradation with AOPs, including ozonation, Fenton and wet air oxidation.

\section{Advanced oxidation processes}

Ozonation. Presently, ozone is one of the most widely used advanced oxidation processes. It has a high standard reduction potential of $2.07 \mathrm{~V}$ and it can oxide most organic and inorganic compounds. Especially,it is known to be a powerful method to decolorize reactive dyes by destroying the chromophoric groups[5]. Ozone decomposition includes two possible degradation pathways: direct oxidation and indirect oxidation, respectively. In the direct oxidation, an ozone molecule attacks an unsaturated bond. Its dipolar structure breaks up the bond. This type of oxidation is selective and only part of the organic compound to be degraded. Under indirect oxidation, the hydroxyl radicals are generated in radical chain reactions and react with organic compound.

Previous study [6] analyzed the decolorization of three kinds of anthraquinone dyes by ozone. The results revealed that ozone treatment was very effective in decolorization of anthraquinone dyes, and 
the decolorization efficiency reached over $87.1 \%$ in 20 minutes. Ozone was applied in raw textile wastewater in a pilot-scale plant to evaluate the pre-ozonation efficiency for removal of color and soluble COD [7]. After $4 \mathrm{~h}$ of ozone treatment with wastewater recirculation, the average efficiencies for color removal were $67.5 \%(\mathrm{pH} 9.1)$ and $40.6 \%(\mathrm{pH} \mathrm{3.0)}$, while COD reduction were $25.5 \%(\mathrm{pH}$ 9.1) and $18.7 \%$ (pH 3.0). Meanwhile, the ozonation enhanced the biodegradability.

The initial concentration of dye, ozone dosage, contact time and $\mathrm{pH}$ can influence the rate of the decolorization[8]. In order to increase the decolorization rate, many catalysts are used in combination with ozone to enhance the oxidation process. Ultrasonic and ultraviolet have been proved as valid catalysts $[9,2]$. The combination with ozone might produce more hydroxyl radicals that accelerate the decolorization.

The advantage of ozone process is that it can be applied in its gaseous state, so it will not increase the volume of wastewater and sludge. However, the industrial applications of ozonation have been limited by the high production cost of ozone and the low ozone utilization due to poor mass transfer rate. So how to improve the ozone transfer rate needs to be further studied.

Fenton process. The Fenton reaction is one of the popular AOP methods for dyes decolorization. It combines $\mathrm{Fe}^{2+}$ and $\mathrm{H}_{2} \mathrm{O}_{2}$ to produce $\bullet \mathrm{OH}$. It is also one of the most practical industrial applications demonstrated in recent years[10]. A typical $\bullet \mathrm{OH}$ formation is shown as:

$$
\mathrm{H}_{2} \mathrm{O}_{2}+\mathrm{Fe}^{2+} \rightarrow \mathrm{Fe}^{3+}+\mathrm{OH}^{-}+\cdot \mathrm{OH}
$$

In addition to the oxidation, the ferric ions generated during the oxidation stage, promote the removal of other pollutants by coagulation and sedimentation [11]. The Fenton reaction has several important advantages. First, Fenton's reagent is relatively cheap. Second, the process is easy to operate and maintain. Third, there is no mass transfer limitation. Forth, reaction time it takes is the shortest among all AOPs.

The application of Fenton oxidation process for the decolorization of an azo dye Direct Blue 15 (DB15) in aqueous solution showed that the DB15 aqueous solution could be completely decolorized by Fenton oxidation within 50 minutes reaction time under the optimal conditions [12]. Fenton oxidation process was used to degrade dye wastewater from the agate industry[13] and the operation results showed that $2 \mathrm{~mL} / \mathrm{L}$ of $\mathrm{H}_{2} \mathrm{O}_{2}(32-36.5 \%)$ and $0.16 \mathrm{~g} / \mathrm{L}$ of $\mathrm{FeSO}_{4}$ dosages were enough to decolorize the effluent, removed suspended solids, reduced the organic content and increased the surface tension.

The main disadvantages of Fenton process are the increasing quality of sludge, and the additional water pollution caused by the homogeneous catalyst that added as an iron salt. So, many attempts have been made to enhance the efficiency based on Fenton process. Photo-Fenton process was used to degrade the Mordant red 73 (MR73) azo dye in water[14]. The results showed that the production of hydroxyl radical increased and achieved $85 \%$ mineralization of the dye in $3 \mathrm{~h}$. The Electro-Fenton process was applied to degrade Sunset Yellow FCF azo dye[15]. Electro-Fenton process achieved complete decolorization and significant mineralization (approximately 97\%) of the dye.

Wet air oxidation process. Wet air oxidation (WAO) is one of the most economical and environmental-friendly AOPs for wastewater treatment, particularly for toxic and high organic content wastewater. Refractory organic pollutants in industrial wastewater can be effectively degraded.Organics or inorganic components are oxidized at elevated temperatures $\left(125-320^{\circ} \mathrm{C}\right)$ and pressures (0.5-20 MPa) using gaseous oxygen (or air) as oxidant [16].Dissolved oxygen provides strong driving force for oxidationin because its solubility is greatly enhanced at elevated temperatures and pressures. The possible decomposition pathway is shown as:

$$
\begin{array}{lll}
\cdot \mathrm{RH}+\mathrm{O}_{2} & \rightarrow & \cdot \mathrm{R}+\cdot \mathrm{HO}_{2} \\
\cdot \mathrm{R}+\cdot \mathrm{R} & \rightarrow & \cdot \mathrm{RO}_{2} \\
\cdot \mathrm{RO}_{2}+\mathrm{RH} & \rightarrow & \mathrm{ROOH}+\cdot \mathrm{R} .
\end{array}
$$


Wet air oxidation process has been used to degrade and mineralize dyes. Comparison study reported when using $\mathrm{UV} / \mathrm{TiO}_{2}$, electro-Fenton (EF), wet air oxidation (WAO), and UV/electro-Fenton (UV/EF) to degrade Reactive Red 120 (RR120) dye in aqueous solution, the most effective one was observed to be the WAO process[17]. Wet air oxidation was applied to treat azo dye solution of cationic red X-GRL[18]. The result showed this type of dyeing wastewater was suitable to be treated by WAO system, while WAO would potentially be cost-effective in decolorization of this kind of wastewater in industry. Although WAO can quickly treat high concentration and highly toxic pollutants, the wide application is limited because of the high capital investments and maintenance costs [19]. As a consequence, considerable attention has been paid to the application of catalysts for the catalytic WAO (CWAO) process. The addition of catalysts, could not only guarantee the process to be carried out at much milder conditions, but also enhance the degradation of organic pollutants and accelerates the rates of oxidation.

The application of CWAO for the decolorization of Basic Yellow 11 (BY11)was successfully carried out at moderate conditions $\left(\mathrm{T}=100-200{ }^{\circ} \mathrm{C}\right.$; oxygen pressure $\left.=30-60 \mathrm{bar}\right)$ using $\mathrm{Ni} / \mathrm{MgAlO}$ as the catalyst[20]. $\mathrm{ZnO} / \mathrm{MoO}_{3}$ nanotube was used as catalyst to degrade wastewater containing $0.3 \mathrm{~g} / \mathrm{L}$ Safranin-T (ST)[21]. It was found the decolorization efficiency and the chemical oxygen demand (COD) removal of ST reached above 98\% and 95\%, respectively, within 18 minutes at room temperature and atmospheric pressure. And the organic pollutants were totally mineralized to simple inorganic species, such as $\mathrm{HCO}_{3}{ }^{-}, \mathrm{Cl}^{-}$and $\mathrm{NO}_{3}{ }^{-}$, while the total organic carbon (TOC) decreased 99.3\%. The azo dye Acid Orange 7 (AO7) was fully degraded by CWAO in acid aqueous media ( $\mathrm{pH}$ $=2.6)$ under moderate conditions $\left(\mathrm{T}=150^{\circ} \mathrm{C}\right.$; oxygen pressure $\left.=0.5 \mathrm{MPa}\right)$. The results showed that the WO degradation of azo dye $\mathrm{AO} 7$ was successfully carried out using $\mathrm{FeCl}_{3} / \mathrm{NaNO}_{2}$ as the catalyst at moderate conditions. When using $10 \mathrm{~mol} \% \mathrm{FeCl}_{3}$ and $60 \mathrm{~mol} \% \mathrm{NaNO}_{2}$ as the catalyst, $56 \% \mathrm{TOC}$ removal could be obtained after $4 \mathrm{~h}$ of reaction at $150^{\circ} \mathrm{C}$ and $0.5 \mathrm{MPa}$ oxygen.

CWAO is an effective advanced oxidation technology, which could be used to degrade and mineralize dyes. Further studies, on developing catalysts that are more active, stable, and effectively utilized in industrial scale, are necessary. Furthermore, the reaction mechanism should be explained more clearly.

\section{Conclusion}

Advanced oxidation processes (AOPs), such as ozonation, Fenton and wet air oxidation, are promising methods to degrade and mineralize dyes. However, most experients were carried out an laboratory. The problem that AOPs are not being applied for industry scales is mainly attributed to the utilization cost. Therefore, the most important issue for the application of AOPs is to reduce the cost. As the analysis above, the solution to lower the cost is to combine the AOPs with other technologies, which contain the US process, the UV process, and the photo process. Moreover, the research about the catalysts combined with AOPs should be further studied. In these ways, the cost may be reduced, and the large scale application for industry dye wastewater treatment would be realized in the near future.

\section{Acknowledgments}

This work was financially supported by National Nature Science Foundation of China (51121062 and 51008105). The authors also gratefully acknowledge the financial support by State key Laboratory of Urban Water Resource and Environment (2014TS06), the Department of Education Fund for Doctoral Tutor (20122302110054), the Harbin Institute of Technology Fund for young top-notch talent teachers (AUGA5710052514). 


\section{References}

[1]Dos Santos, A.B., F.J. Cervantes, and J.B. van Lier, Review paper on current technologies for decolourisation of textile wastewaters: perspectives for anaerobic biotechnology. Bioresour Technol, 2007. 98(12): p. 2369-85.

[2]Zhou, X.J., et al., Ultrasonic-assisted ozone oxidation process of triphenylmethane dye degradation: evidence for the promotion effects of ultrasonic on malachite green decolorization and degradation mechanism. Bioresour Technol, 2013. 128: p. 827-30.

[3] Basiri Parsa, J. and S. Hagh Negahdar, Treatment of wastewater containing Acid Blue 92 dye by advanced ozone-based oxidation methods. Separation and Purification Technology, 2012. 98: p. 315-320.

[4] Zhou, M. and J. He, Degradation of azo dye by three clean advanced oxidation processes: Wet oxidation, electrochemical oxidation and wet electrochemical oxidation-A comparative study. Electrochimica Acta, 2007. 53(4): p. 1902-1910.

[5] Sharma, S., et al., Studies on Degradation of Reactive Red 135 Dye in Wastewater using Ozone. Procedia Engineering, 2013. 51: p. 451-455.

[6] Liu, J.-1., H.-j. Luo, and C.-h. Wei, Degradation of anthraquinone dyes by ozone. Transactions of Nonferrous Metals Society of China, 2007. 17(4): p. 880-886.

[7] Somensi, C.A., et al., Use of ozone in a pilot-scale plant for textile wastewater pre-treatment: physico-chemical efficiency, degradation by-products identification and environmental toxicity of treated wastewater. J Hazard Mater, 2010. 175(1-3): p. 235-40.

[8] Chen, T.Y., et al., Application of ozone on the decolorization of reactive dyes - Orange-13 and Blue-19. Desalination, 2009. 249(3): p. 1238-1242.

[9] Cuiping, B., et al., Removal of rhodamine B by ozone-based advanced oxidation process. Desalination, 2011. 278(1-3): p. 84-90.

[10] Meric, S., D. Kaptan, and T. Olmez, Color and COD removal from wastewater containing Reactive Black 5 using Fenton's oxidation process. Chemosphere, 2004. 54(3): p. 435-41.

[11] Faouzi, M., et al., Advanced oxidation processes for the treatment of wastes polluted with azoic dyes. Electrochimica Acta, 2006. 52(1): p. 325-331.

[12] Sun, J.-H., et al., Fenton oxidative decolorization of the azo dye Direct Blue 15 in aqueous solution. Chemical Engineering Journal, 2009. 155(3): p. 680-683.

[13] Barros, A.L., et al., Decolorizing dye wastewater from the agate industry with Fenton oxidation process. Minerals Engineering, 2006. 19(1): p. 87-90.

[14] Elmorsi, T.M., et al., Decolorization of Mordant red 73 azo dye in water using H2O2/UV and photo-Fenton treatment. J Hazard Mater, 2010. 174(1-3): p. 352-358.

[15] Ghoneim, M.M., H.S. El-Desoky, and N.M. Zidan, Electro-Fenton oxidation of Sunset Yellow FCF azo-dye in aqueous solutions. Desalination, 2011. 274(1-3): p. 22-30.

[16] Fu, J. and G.Z. Kyzas, Wet air oxidation for the decolorization of dye wastewater: An overview of the last two decades. Chinese Journal of Catalysis, 2014. 35(1): p. 1-7.

[17] Kusvuran, E., et al., Comparison of several advanced oxidation processes for the decolorization of Reactive Red 120 azo dye in aqueous solution. J Hazard Mater, 2004. 109(1-3): p. 85-93.

[18]Lei, L., et al., Decolorization of cationic red X-GRL by wet air oxidation: performance optimization and degradation mechanism. Chemosphere, 2007. 68(6): p. 1135-42.

[19] Duprez, D., et al., Catalytic oxidation of organic compounds in aqueous media. Catalysis Today, 1996. 29(1-4): p. 317-322.

[20] Ovejero, G., et al., Catalytic wet air oxidation of a non-azo dye with Ni/MgAlO catalyst. Chemical Engineering Journal, 2013. 215-216: p. 168-173.

[21] Huang, J., et al., $\mathrm{ZnO} / \mathrm{MoO} 3$ mixed oxide nanotube: A highly efficient and stable catalyst for degradation of dye by air under room conditions. Applied Surface Science, 2010. 257(1): p. 116-121. 